\title{
Quality of life impairment associated with body dissatisfaction in a general population sample of women
}

\author{
Jonathan Mond ${ }^{1 *}$, Deborah Mitchison ${ }^{2}$, Janet Latner ${ }^{3}$, Phillipa Hay $^{4,5}$, Cathy Owen $^{6}$ and Bryan Rodgers ${ }^{7}$
}

\begin{abstract}
Background: In order to elucidate the individual and community health burden of body dissatisfaction (BD), we examined impairment in quality of life associated with $\mathrm{BD}$ in a large, general population sample of women.

Methods: Self-report measures of BD, health-related quality of life (SF-12 Physical and Mental Component Summary scales) and subjective quality of life (WHOQOL-BREF Psychological Functioning and Social Relationships subscales) were completed by 5,255 Australian women aged 18 to 42 years.

Results: Most participants (86.9\%) reported some level of dissatisfaction with their weight or shape and more than one third (39.4\%) reported moderate to marked dissatisfaction. Higher levels of BD were associated with poorer quality of life for all items of both quality of life measures, the degree of impairment being proportional to the degree of $\mathrm{BD}$. Associations were strongest for items tapping mental health and psychosocial functioning, although greater BD was associated with substantially increased risk of impairment in certain aspects of physical health even when controlling for body weight. Post-hoc analysis indicated that the observed associations between $\mathrm{BD}$ and quality of life impairment were not accounted for by an association between BD and eating disorder symptoms.

Conclusions: In women, BD is associated with marked impairment in aspects of quality of life relating to mental health and psycho-social functioning and at least some aspects of physical health, independent of its association with body weight and eating disorder symptoms. Greater attention may need to be given to BD as a public health problem. The fact that BD is "normative" should not be taken to infer that it is benign.
\end{abstract}

Keywords: Body dissatisfaction, Prevalence, Disability, Quality of life impairment, Health burden

\section{Background}

In epidemiologic and public health research, non-fatal health conditions are deemed to constitute a public health problem to the extent that they are both prevalent and disabling [1]. Disability is often assessed using one or more measures of health-related quality of life, that is, measures of the perceived effect of an individual's health on his or her everyday functioning [2,3], although individuals' subjective satisfaction with different facets of their lives including, but not limited to, their health status - is considered equally important by many authorities [4,5]. Individuals' subjective satisfaction with their lives may be

\footnotetext{
* Correspondence: Jonathan.Mond@anu.edu.au

${ }^{1}$ Research School of Psychology, Australian National University, Canberra ACT 0200, Australia

Full list of author information is available at the end of the article
}

referred to as subjective quality of life, although it needs to be recognized that all quality of life measures are subjective to some extent and that there are no universally accepted definitions of such terms [5,6]. Both health-related quality of life and subjective quality of life have been found to be strongly predictive of more objective indices of health status, including chronic disease and mortality, as well as health service utilization, hence their utility as measures of disease burden [7-9].

There is no doubt that body dissatisfaction (BD) is prevalent. Findings from epidemiological studies have consistently shown that many, if not most, younger women in industrialized nations are at least moderately dissatisfied with their body weight or shape [10]. The term "normative discontent" was introduced in the 1980's to describe the pervasiveness of this phenomenon and it is

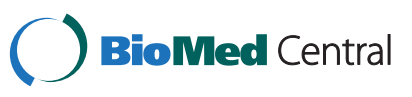


no less apposite today $[10,11]$. BD remains less common in men, although the gap may be closing $[10,12]$.

Whether and to what extent BD should be considered disabling is less clear. On the one hand, there is good evidence that $\mathrm{BD}$ is associated with - and predictive of - a range of adverse health outcomes, including low self-esteem, depressive mood and eating disorder symptoms [13-15]. There is also good evidence that $\mathrm{BD}$ mediates the association between obesity and emotional well-being, in young women at least $[12,16]$. On the other hand, attention has focused, almost without exception, on the status of BD as a risk factor for other, "more serious" mental health problems rather than as a public health problem in its own right $[13,17,18]$. As a consequence, little is known about the effects of $\mathrm{BD}$ on quality of life. Given the demonstrated links between $\mathrm{BD}$ and impairment in emotional well-being [13-15], adverse effects of BD on quality of life might be expected to be most pronounced for items tapping perceived impairment in mental health and psycho-social functioning, whereas impairment in physical health might be expected to be less pronounced and due, at least in part, to the positive association between $\mathrm{BD}$ and body weight [12]. However, the available evidence does not permit any firm conclusions in this regard.

Meland and colleagues [19] found, in a large, general population sample of adolescents, that perceived negative health was more common among girls than among boys and that this was accounted for by higher levels of $\mathrm{BD}$ - and a stronger association between $\mathrm{BD}$ and perceptions of health - among girls. However, findings from this study are difficult to interpret because the assessment of perceived health was confined to a single item, namely, "How healthy do you think you are?", that presumably encompassed perceived impairment in both physical and mental health [20]. Further, no attempt was made to control for body weight in exploring the associations between BD and perceptions of health.

Muennig and colleagues [21] found, in a general population sample of women and men, that the difference between actual and desired weight was a better predictor of self-reported "unhealthy" days in the past month than actual body weight and that this was the case for both physical and mental health. Further, and consistent with the findings of Meland et al. [19], poor self-reported health was more common in women than in men and this was accounted for, at least in part, by higher levels of $\mathrm{BD}$, and a stronger association between $\mathrm{BD}$ and perceived impairment, in women.

Of note is that there was no assessment of eating disorder symptoms, namely, the "undue influence of weight or shape on self-evaluation" and the occurrence of binge eating and/or extreme weight-control behaviors [20,22], in either of these studies. Given the strong links between
$\mathrm{BD}$ and eating disorder symptoms [18], and given that eating disorder symptoms are associated with marked impairment in quality of life [20,22-24], it would be helpful to consider the potential role of these symptoms in accounting for any observed associations between BD and quality of life impairment. In a community-based study of quality of life impairment associated with eating disorder symptoms in women, Vallance and colleagues [25] found moderate negative correlations between BD and both physical and mental component summary scales of the (36-item) Medical Outcomes Study Short Form (SF-36) in preliminary (bivariate) analysis. Whether these associations might have been due to an association between $\mathrm{BD}$ and eating disorder symptoms was not, however, considered.

To our knowledge, no other research has examined the association between $\mathrm{BD}$ and impairment in quality of life in a general population sample. This is regrettable because population-based research addressing impairment in quality of life associated with $\mathrm{BD}$, when taken with findings relating to prevalence, has the potential to highlight the significance of $\mathrm{BD}$ as a public health problem - and, in turn, the need for a public health response in the same way that findings from epidemiological studies of disability associated with the more common mental health problems have highlighted the public health burden of these conditions $[3,23,26]$.

The goal of the present study was, therefore, to examine impairment in quality of life associated with the spectrum of BD that occurs at the population level, using measures of both health-related and subjective quality of life. Although the existing evidence did not permit any firm a priori hypotheses, it was reasonable to surmise that adverse effects of BD on quality of life would be most pronounced for items tapping perceived impairment in or dissatisfaction with mental health and psycho-social functioning, whereas impairment in physical health associated with BD would be expected to be less pronounced and due, at least in part, to the association between $\mathrm{BD}$ and body weight. A secondary aim of the study was to determine whether any observed associations between BD and quality of life impairment could be accounted for by an association between BD and eating disorder symptoms.

\section{Methods}

\section{Study design and participants}

The research was conducted as part of the Health and Well-Being of Female ACT Residents Study, an epidemiological study of disability associated with eating disorder symptoms among women in the general population $[22,23,27,28]$. Participants were residents of the Australian Capital Territory (ACT) region of Australia, which includes the city of Canberra (population of approximately 
314,000 in 2002). All aspects of the study were approved by the ACT Human Research Ethics Committee.

At the first phase of the study, self-report questionnaires were posted to a sample of 10,000 female ACT residents aged 18-42 years, selected at random from the electoral roll and stratified by age in 5-year bands (18-22 years, 23-27 years, 28-32 years, 33-37 years, and 38-42 years) (in Australia, inclusion on the Electoral Roll is a legal requirement for residents aged 18 years or more). The questionnaire included measures of eating disorder symptoms, health-related quality of life, subjective quality of life and socio-demographic information. Body mass index (BMI, $\mathrm{kg} / \mathrm{m}^{2}$ ) was calculated from self-reported height and weight. In pilot work, we found a very high correlation $(r=.97)$ between BMI calculated in this way and BMI calculated according to actual (measured) height and weight [29].

Completed questionnaires were received, following reminder letters, from 5,255 individuals, which represented a response rate of $57.1 \%$ after incorrectly listed addresses $(n=684)$ and individuals away from home at the time of the survey $(n=112)$ were taken into account. This is a conservative estimate of true response because not all individuals with incorrectly listed addresses would have been identified [30]. The sample comprised approximately $10 \%$ of the total population of women aged 18 to 42 years in the ACT region and was representative of this population on a range of socio-demographic variables, including marital status, employment status, highest level of education completed, parity, and first language [28].

The ACT is a highly urbanized region and this was reflected in the characteristics of participants. Thus, most participants (85.3\%) were born in Australia, had English as their first language (91.8\%) and had completed 12 or more years of formal education (90.5\%). A majority of participants (55\%) were married or living as married, $43.8 \%$ had one or more children, $62.8 \%$ were employed full- or part-time, $15.6 \%$ were full-time students and $17.5 \%$ nominated home duties as their main activity. Participants' mean (SD) age was 30.3 (7.2) years. Their mean $(S D)$ BMI was $24.5(5.3) \mathrm{kg} / \mathrm{m}^{2}$.

\section{Study measures \\ Body dissatisfaction}

BD was assessed using two items of the measure of eating disorder symptoms, namely, the Eating Disorder Examination Questionnaire (EDE-Q). The EDE-Q [31] is a widely-used, 36-item self-report measure that focuses on the past 28 days. Subscale scores and a global score may be derived from 22 items that assess key attitudinal features, namely, concerns about dietary intake, concerns about eating, concerns about weight and concerns about shape, whereas remaining items assess the occurrence and frequency of eating disorder behaviors, namely, binge eating, self-induced vomiting, misuse of laxatives or diuretics, extreme dietary restriction and excessive exercise [28,29].

Two of the items comprising the EDE-Q weight/shape concerns subscales specifically assess body dissatisfaction, namely, "How dissatisfied have you felt about your weight" and "How dissatisfied have you felt about your shape"? Response options for these items range from 0 to 6 with higher scores indicating greater dissatisfaction and with descriptors indicating that scores of "0", " 2 ", " 4 " and "6" correspond to being "not at all", "slightly", "moderately" and "markedly" dissatisfied, respectively. Since scores on these items were highly correlated $(r=0.89)$, a single "dissatisfaction with weight or shape" score was obtained as the simple average of scores on the items concerned.

\section{Health-related quality of life}

Health-related quality of life was assessed using the Medical Outcomes Study (12-item) Short-Form disability scale (SF-12) [32]. Items of the SF-12 are summarised into two weighted scales (Physical Component Summary scale, PCS; Mental Component Summary scale, MCS), designed to assess physical and mental health impairment. Each scale is scored to have a mean of 50 and standard deviation of 10, with lower scores indicating higher levels of impairment. The SF-12 has very good psychometric properties, including demonstrated validity in the Australian population $[3,26,32]$. PCS items include, for example, "Does your health now limit you in moderate activities, such as moving a table, vacuuming or playing golf?" and "During the past four weeks, were you limited in the kind or work or other activities undertaken as a result of your physical health?", whereas MCS items include, for example, "During the past four weeks have you accomplished less than you would like as a result of any emotional problems?" and "During the past four weeks how much of the time have you felt calm and peaceful"? The item response scheme is variable across the items, some items being dichotomous and others having 3, 5 or 6 response options.

\section{Subjective quality of life}

Subjective quality of life was assessed using the World Health Organization Brief Quality of Life Assessment Scale (WHOQOL-BREF), a 26-item measure yielding scores on each of four domains relating to the individual's subjective evaluation of his/her physical health, environmental health, psychological functioning and social relationships [33,34]. Items are scored on a five-point, Likert-type scale, with scores of " 1 " and " 5 " indicating, respectively, extreme dissatisfaction and extreme satisfaction. Only items comprising the Psychological Functioning (QOL-P; 6 items) and Social Relationships (QOL-S; 3 items) domains were included in the Health and Well-Being Study [35,36]. 
Items of the QOL-P include, for example, "To what extent do you feel your life to be meaningful"? and "How satisfied are you with yourself?', whereas items of the QOL-S include, for example, "How satisfied are you with your personal relationships"? and "How satisfied are you with the support you get from your friends?" One of the QOL-P items, which explicitly addresses satisfaction with bodily appearance, was excluded from the analysis, whereas an additional item of the WHOQOL-BREF, which assesses overall satisfaction with quality of life, and which does not contribute to subscale scores, was included.

\section{Statistical analysis}

Since averaging scores on the items assessing BD dissatisfaction with weight and shape had the effect of introducing non-integer values (i.e., 0.5, 1.5, 2.5, etc.), scores on the $\mathrm{BD}$ variable were first recoded so as to preserve the original (7-point) ordinal coding scheme. That is, scores of " 0.5 " and " 1.5 " were recoded to " 1 ", scores of " 2.5 " and " 3.5 " were recoded to " 3 ", and so on. This transformation would have had little impact, since most participants $(69.2 \%)$ had the same score on the original ("dissatisfaction with weight", "dissatisfaction with shape") items.

Both summary-scale and item-level analysis were conducted to examine the associations between $\mathrm{BD}$ and impairment in specific aspects of quality of life. Bivariate associations between BD and scores on summary scales measures, namely, the SF-12 PCS and MCS and WHO QOL-BREF QOL-P and QOL-S, were calculated using the Spearman rank order correlation coefficient (Spearman's rho), whereas analysis of variance was used to compare mean summary scale scores on each measure between subgroups of participants reporting different levels of body dissatisfaction. For analysis involving PCS and MCS summary scores, both the standard scoring method, employing factor scores derived by means of orthogonal factor rotation, and an alternative method, employing factor scores derived by means of oblique factor rotation, were employed [37]. Since the results were unchanged, only findings based on the standard scoring method are reported. For the item-level analysis, a series of ordinal logistic regression analyses was conducted, with each of the SF-12 and WHOQOL-BREF items as outcome variables, in order to examine the likelihood of reporting quality of life impairment for participants with each of the 6 non-zero levels of $\mathrm{BD}$ (BD1-BD6) relative to participants with no BD (BD0).

To address the possibility that any observed associations between $\mathrm{BD}$ and quality of life impairment were due to an association between $\mathrm{BD}$ and eating disorder symptoms, the regression analysis was repeated controlling for the occurrence of eating disorder symptoms. Participants with eating disorder symptoms ("probable eating disorder cases") were identified using an operational definition employed in previous, population-based research, namely, the "undue influence of weight or shape on self-evaluation" in conjunction with the regular occurrence of any eating disorder (binge eating or extreme weight-control) behavior $[23,38]$. The "undue influence of weight or shape on self-evaluation", which is correlated with but distinct from BD [39] and which is included among the diagnostic criteria for both anorexia nervosa and bulimia nervosa [40], was defined as a score of 5 or 6 on either or both of the two EDE-Q items that assess this construct [23,41]. For binge eating, self-induced vomiting and misuse of laxatives or diuretics, "regular" was defined as "at least weekly". "Regular extreme dietary restriction" was defined as "going without food for a period of 8 or more waking hours to influence weight or shape, on average, three or more times per week", whereas "regular excessive exercise" was defined as "exercising hard to influence weight or shape, on average, five or more times per week" [28]. This operational definition has been found to identify a highly symptomatic subgroup of women, in terms of eating disorder and comorbid psychopathology, in previous, population-based research [23,38].

Covariates included in all analysis were: age; BMI; marital status; employment status; educational attainment; parity (children, no children); first language (English, not English); country of birth (Australia, not Australia); and (as a proxy for income) possession of private health insurance. Complete case analysis (listwise deletion of missing values) was employed. Levels of missing data were $<2.0 \%$ for the variables considered in the current study, with the exception of the BMI variable for which data were missing for 363 participants (6.9\%). The maximum effective sample size for the current study analyses was, therefore, 4,892 [16,23]. A significance level of .05 was used for all tests and all analysis was conducted using the Statistical Package for the Social Sciences (SPSS) v.21.0.

\section{Results}

As can be seen in Table 1, BD was common in this sample with most participants (86.9\%) reporting some degree of dissatisfaction with their weight or shape and more than one third (36.6\%) reporting moderate to marked dissatisfaction.

Also shown in Table 1 are mean scores on each of the four summary QoL measures for participants reporting different levels of BD. As can be seen, higher levels of $\mathrm{BD}$ were associated with lower scores on all four summary scale measures, SF-12 PCS, SF-12 MCS, QOL-P and QOL-S, although the effect size for the difference between groups on the SF-12 PCS was small. The rank order correlations between BD and scores on SF-12 
Table 1 Mean (SE) scores on measures of health-related quality of life (SF-12 Physical and Mental Component Summary scales; SF-12 PCS, MCS) and subjective quality of life (WHOQOL-BREF Psychological and Social Functioning subscales; QOL-P, QOL-S) among participants (n=4,892) reporting each of 7 levels of body dissatisfaction (BD0-BD6)

\begin{tabular}{|c|c|c|c|c|c|c|c|c|c|c|c|}
\hline & $\begin{array}{c}\text { Not at all } \\
\text { dissatisfied } \\
\text { (BD0) }\end{array}$ & $\begin{array}{l}\text { Not at all/ slightly } \\
\text { dissatisfied } \\
\text { (BD1) }\end{array}$ & (BD1) & $\begin{array}{l}\text { Slightly/ moderately } \\
\text { dissatisfied } \\
\text { (BD1) }\end{array}$ & $\begin{array}{l}\text { Moderately } \\
\text { dissatisfied } \\
\text { (BD1) }\end{array}$ & $\begin{array}{l}\text { Moderately/ markedly } \\
\text { dissatisfied } \\
\text { (BD1) }\end{array}$ & $\begin{array}{c}\text { Markedly } \\
\text { dissatisfied } \\
\text { (BD1) }\end{array}$ & & & & \\
\hline$n$ & 674 & 1264 & 647 & 687 & 594 & 598 & 695 & & & & \\
\hline \multirow[t]{2}{*}{$\%$} & 13.1 & 24.5 & 12.5 & 13.3 & 11.5 & 11.6 & 13.5 & & & & \\
\hline & Mean (SE) & Mean $(S E)$ & Mean (SE) & Mean $(S E)$ & Mean (SE) & Mean (SE) & Mean (SE) & $F$ & $p$ & Post-Hoc ${ }^{\mathrm{ii}}$ & Effect Size $\mathrm{iii}^{\mathrm{ii}}$ \\
\hline SF-12 PCS & $49.63(.38)$ & $49.79(.27)$ & $50.41(.36)$ & $50.46(.35)$ & $50.10(.39)$ & 49.75 (.38) & $48.64(.38)$ & 2.74 & $<.05$ & $2,3>6$ & .01 \\
\hline SF-12 MCS & $50.90(.46)$ & $49.04(.33)$ & $47.44(.44)$ & $44.79(.43)$ & $45.47(.47)$ & $41.25(.46)$ & $38.59(.47)$ & 81.47 & $<.01$ & $0>1,2>3,4>5>6$ & .11 \\
\hline QOL-P & $3.98(.03)$ & $3.82(.02)$ & $3.77(.03)$ & $3.63(.02)$ & $3.60(.03)$ & $3.38(.03)$ & $3.14(.03)$ & 107.57 & $<.01$ & $0>1,2>3,4>5>6$ & .14 \\
\hline QOL-S & $4.08(.03)$ & $3.92(.02)$ & $3.85(.03)$ & $3.71(.03)$ & $3.65(.04)$ & $3.48(.03)$ & $3.33(.03)$ & 53.21 & $<.01$ & $0>1,2,3>4>5>6 ; 1>3$ & .07 \\
\hline
\end{tabular}

'Lower scores indicate higher levels of impairment on all measures. Means were adjusted for the following covariates: age, BMl; marital status; employment status; level of education; parity; first language, country of birth and possession of private health insurance.

iipost-hoc tests were adjusted using the Bonferroni correction.

iiipartial eta-squared: values of approximately .01, .06, and .14, indicate, small, medium, and large effect sizes, respectively [42]. 
PCS, SF-12 MCS, QOL-P, and QOL-S, were, respectively, $-.10,-.30,-.36$ and -.26 . The correlation between BD and BMI was .47.

Results of the ordinal logistic regression analyses are summarised in Table 2. As can be seen, all levels of BD were associated with impairment in at least some aspects of quality of life, after controlling for BMI and other potential covariates. Further, the number of items for which BD was associated with increased likelihood of quality of life impairment increased proportional to the level of $\mathrm{BD}$ reported.

As is also apparent in Table 2, increased likelihood of quality of life impairment associated with BD was more likely to be observed for items of the SF-12 tapping mental health than those tapping physical health, although greater BD was strongly associated with increased likelihood of impairment for certain aspects of physical health. In particular, participants who reported marked $\mathrm{BD}$ were 3.75 times more likely to report poorer perceived general health than those who reported no BD, after controlling for age, BMI and socio-demographic characteristics.

As would be expected, individuals with eating disorder symptoms $(\mathrm{n}=482,9.2 \%)$ were over-represented among participants with moderate $(B D=5: 19.2 \%)$ and marked $(\mathrm{BD}=6: 43.3 \%) \mathrm{BD}$, whereas the prevalence of eating disorder symptoms was low in the remainder of the study population, ranging from $0.4 \%$ among participants with no $\mathrm{BD}$ to $3.8 \%$ among participants with moderate BD $\left(\chi^{2}=1300.0, \mathrm{p}<.01\right)$. As would also be expected, effect sizes for some associations were reduced when the regression analysis was repeated controlling for the occurrence of eating disorder symptoms. For example, the odds ratio for the SF-12 PCS General Health item for participants who reported marked BD changed from 3.75 to 3.50 , whereas the odds ratio for the SF-12 MCS Blue/Sad item for participants who reported marked BD changed from 7.49 to 5.79 . However, the pattern of findings was unchanged and all previously significant effects remained significant.

\section{Discussion}

\section{Summary of main findings}

We examined impairment in health-related and subjective quality of life associated with $\mathrm{BD}$ in a large, general population sample of women. Most participants (86.9\%) reported some level of dissatisfaction with their weight or shape and more than one third (39.4\%) reported moderate to marked dissatisfaction. Higher levels of BD were associated with poorer quality of life for all items of both quality of life measures, the degree of impairment being proportional to the degree of dissatisfaction. Associations were strongest for items tapping mental health and psychosocial functioning, although greater
BD was associated with substantially increased risk of impairment in certain aspects of physical health even when controlling for body weight. Post-hoc analysis suggested that the observed associations between $\mathrm{BD}$ and quality of life impairment were not due to an association between BD and eating disorder symptoms.

\section{Study implications}

To our knowledge, this is the first study to consider impairment in quality of life associated with BD in a large, general population sample of women. The most notable finding was that BD was associated with marked impairment in various aspects of quality of life in a substantial proportion of participants. This finding is notable because interest in BD has, thus far, been largely confined to its role as a risk factor for "more adverse" outcomes, such as low self-esteem, depressive mood and eating disorder symptoms $[13,17,18]$. When both the prevalence of $\mathrm{BD}$ and the degree of associated impairment are considered, it is apparent that there is a very substantial public health burden of $\mathrm{BD}$ at the population level. Hence, the present findings suggest that greater attention may need to be given to $\mathrm{BD}$ as a public health problem in its own right. Some, tentative steps in this direction are now being taken, for example, in the form of government-sanctioned, though voluntary, regulations relating to the depiction of body image in the popular media [17], but there is little in the way of a coordinated, public health approach. We hope that the present findings will serve as an incentive for action in this regard. An additional implication of the present findings is that the fact that dissatisfaction with weight or shape is "normative" in industrialized nations should not be taken to infer that it is benign.

As expected, impairment in quality of life associated with $\mathrm{BD}$ was more likely to be observed for items tapping mental health and psycho-social functioning than for those tapping physical health status. Nevertheless, moderate to marked BD was found to be associated with substantially increased risk of impairment in certain aspects of physical health even after controlling for age, body weight and socio-demographic characteristics. The explanation for these latter associations is unclear. Muennig and colleagues [21], who similarly found, in a general population sample of women and men, that BD was independently associated with both physical and mental health impairment, suggested that stress associated with negative body image may mediate the association between $\mathrm{BD}$ and physical health impairment. Alternatively, or in addition, personality characteristics associated with BD, such as low self-esteem, depressive mood and perfectionism, may be conducive to an unduly negative appraisal of physical health [43]. Along similar lines, it would not be surprising, given the pervasiveness 
Table 2 Results of ordinal logistic regression analyses showing odds ratios (ORs) and confidence intervals (Cls) for poorer quality of life on items of the WHOQOL-BREF and SF-12, according to participants' ( $n=4,892$ ) level of body dissatisfaction (BD) ${ }^{\text {i-iii }}$

\begin{tabular}{|c|c|c|c|c|c|c|}
\hline & $\begin{array}{c}\text { BD1 } \\
\text { OR (95\% Cl) }\end{array}$ & $\begin{array}{c}\text { BD2 } \\
\text { OR }(95 \% \mathrm{Cl})\end{array}$ & $\begin{array}{c}\text { BD3 } \\
\text { OR }(95 \% \mathrm{Cl})\end{array}$ & $\begin{array}{c}\text { BD4 } \\
\text { OR }(95 \% \mathrm{Cl})\end{array}$ & $\begin{array}{c}\text { BD5 } \\
\text { OR }(95 \% \mathrm{Cl})\end{array}$ & $\begin{array}{c}\text { BD6 } \\
\text { OR }(95 \% \mathrm{Cl})\end{array}$ \\
\hline \multicolumn{7}{|l|}{ WHOQOL-BREF items } \\
\hline \multicolumn{7}{|c|}{ Psychological Functioning ${ }^{i v}$} \\
\hline Positive Feelings & $1.22(0.98,1.52)$ & $1.49(1.18,1.87)^{* *}$ & $1.86(1.44,2.41)^{* * *}$ & $2.02(1.59,2.58)^{* * *}$ & $3.23(2.47,4.21)^{* * *}$ & $4.04(3.12,5.22)^{* * *}$ \\
\hline Spirituality & $1.45(1.18,1.78)^{* * *}$ & $1.70(1.37,2.11)^{* * *}$ & $2.27(1.78,2.89)^{* * *}$ & $2.54(2.02,3.20)^{* * *}$ & $3.39(2.63,4.36)^{* * *}$ & $4.98(3.90,6.36)^{* * *}$ \\
\hline Thinking & $1.29(1.04,1.59)^{*}$ & $1.37(1.10,1.70)^{* *}$ & $1.80(1.40,2.32)^{* * *}$ & $2.00(1.58,2.53)^{* * *}$ & $2.93(2.26,3.79)^{* * *}$ & $4.21(3.28,5.41)^{* * *}$ \\
\hline Self-esteem & $1.84(1.47,2.30)^{* * *}$ & $2.60(2.07,3.27)^{* * *}$ & $3.89(3.01,5.04)^{* * *}$ & $5.00(3.91,6.38)^{* * *}$ & $9.35(7.15,12.23)^{* * *}$ & $24.58(18.83,32.07)^{* * *}$ \\
\hline Negative feelings & $1.52(1.22,1.88)^{* * *}$ & $1.72(1.37,2.15)^{* * *}$ & $2.41(1.87,3.10)^{* * *}$ & $2.83(2.23,3.59)^{* * *}$ & $4.45(3.43,5.77)^{* * *}$ & $8.47(6.56,10.94)^{* * *}$ \\
\hline \multicolumn{7}{|l|}{ Social Relationships ${ }^{v}$} \\
\hline Personal relationships & $1.53(1.24,1.89)^{* * *}$ & $1.64(1.32,2.04)^{* * *}$ & $2.18(1.70,2.78)^{* * *}$ & $2.81(2.23,3.54)^{* * *}$ & $3.79(2.93,4.89)^{* * *}$ & $4.33(3.38,5.55)^{* * *}$ \\
\hline Sexual activity & $1.34(1.10,1.65)^{* *}$ & $1.68(1.36,2.07)^{* * *}$ & $1.91(1.51,2.42)^{* * *}$ & $2.39(1.91,2.99)^{* * *}$ & $3.22(2.52,4.11)^{* * *}$ & $3.78(2.98,4.81)^{* * *}$ \\
\hline Social support & $1.26(1.02,1.54)^{*}$ & $1.63(1.32,2.02)^{* * *}$ & $1.94(1.53,2.47)^{* * *}$ & $2.06(1.64,2.58)^{* * *}$ & $2.63(2.05,3.38)^{* * *}$ & $3.81(2.99,4.85)^{* * *}$ \\
\hline Overall quality of lifevi & $1.26(1.02,1.57)^{*}$ & $1.38(1.10,1.72)^{* *}$ & $1.69(1.31,2.18)^{* * *}$ & $2.06(1.62,2.62)^{* * *}$ & $2.55(1.96,3.31)^{* * *}$ & $3.60(2.78,4.65)^{* * * *}$ \\
\hline \multicolumn{7}{|l|}{ SF-12 items } \\
\hline \multicolumn{7}{|l|}{ Physical Health vii } \\
\hline General health & $1.25(1.02,1.53)^{*}$ & $1.37(1.11,1.69)^{* *}$ & $1.52(1.20,1.93)^{* *}$ & $1.90(1.51,2.38)^{* * *}$ & $2.17(1.70,2.77)^{* * *}$ & $3.75(2.95,4.77)^{* * *}$ \\
\hline Accomplish less & $1.00(0.78,1.28)$ & $1.01(0.79,1.31)$ & $1.34(1.01,1.77)^{*}$ & $1.40(1.07,1.82)^{*}$ & $1.43(1.07,1.91)^{*}$ & $2.44(1.86,3.21)^{* * *}$ \\
\hline Limited in kind & $1.00(0.77,1.31)$ & $1.08(0.82,1.42)$ & $1.00(0.73,1.36)$ & $1.12(0.84,1.50)$ & $1.43(1.06,1.95)^{*}$ & $1.73(1.30,2.32)^{* * *}$ \\
\hline Moderate activities & $0.71(0.53,0.95)^{*}$ & $0.67(0.49,0.91)^{*}$ & $0.62(0.44,0.89)^{* *}$ & $0.64(0.46,0.89)^{* *}$ & $0.87(0.62,1.22)$ & $1.03(0.75,1.41)$ \\
\hline Climb several flights & $0.87(0.65,1.16)$ & $0.82(0.61,1.11)$ & $0.91(0.66,1.27)$ & $0.95(0.70,1.29)$ & $1.30(0.94,1.78)$ & $1.58(1.17,2.14)^{* *}$ \\
\hline Pain-interfere & $1.23(1.00,1.52)$ & $1.20(0.97,1.49)$ & $1.36(1.07,1.74)^{*}$ & $1.59(1.27,2.01)^{* * *}$ & $1.51(1.17,1.95)^{* *}$ & $2.12(1.66,2.70)^{* * *}$ \\
\hline \multicolumn{7}{|l|}{ Mental Health ${ }^{\text {viii }}$} \\
\hline Accomplish less & $1.23(0.95,1.60)$ & $1.77(1.36,2.31)^{* * *}$ & $2.64(1.98,3.54)^{* * *}$ & $2.33(1.77,3.08)^{* * *}$ & $4.10(3.05,5.52)^{* * *}$ & $6.25(4.67,8.36)^{* * *}$ \\
\hline Not careful & $1.21(0.91,1.60)$ & $1.62(1.21,2.16)^{* *}$ & $2.57(1.88,3.50)^{* * *}$ & $2.29(1.70,3.08)^{* * *}$ & $3.53(2.58,4.82)^{* * * *}$ & $5.09(3.75,6.89)^{* * *}$ \\
\hline Peaceful & $1.53(1.24,1.87)^{* * *}$ & $1.95(1.58,2.42)^{* * *}$ & $2.62(2.06,3.32)^{* * *}$ & $2.94(2.35,3.69)^{* * *}$ & $4.34(3.40,5.56)^{* * *}$ & $6.71(5.27,8.55)^{* * *}$ \\
\hline
\end{tabular}


Table 2 Results of ordinal logistic regression analyses showing odds ratios (ORs) and confidence intervals (Cls) for poorer quality of life on items of the WHOQOL-BREF and SF-12, according to participants' $(n=4,892)$ level of body dissatisfaction (BD) ${ }^{\text {i-iii }}$ (Continued)

\begin{tabular}{lccccc}
\hline Energy & $1.25(1.02,1.53)^{*}$ & $1.50(1.22,1.85)^{* * *}$ & $2.09(1.65,2.64)^{* * *}$ & $2.36(1.89,2.95)^{* * *}$ & $3.98(3.11,5.08)^{* * *}$ \\
Blue/sad & $1.57(1.27,1.94)^{* * *}$ & $1.86(1.49,2.32)^{* * *}$ & $2.51(1.96,3.22)^{* * *}$ & $2.78(2.20,3.50)^{* * *}$ & $4.55(3.53,5.87)^{* * *}$ \\
Social-time & $1.12(0.90,1.39)$ & $1.33(1.06,1.66)^{*}$ & $1.96(1.53,2.52)^{* * *}$ & $1.71(1.35,2.16)^{* * *}$ & $2.55(1.98,3.28)^{* * *}$ \\
\hline
\end{tabular}

'For all items, odds ratios greater than 1.0 indicate increased likelihood of greater quality of life impairment for the item concerned for participants reporting non-zero levels of body dissatisfaction (BD1 - BD6), relative to participants who reported no body dissatisfaction (BD0). BD1 = none/slight body dissatisfaction; BD2 = slight body dissatisfaction; BD3 = slight/moderate body dissatisfaction; BD4 = moderate body dissatisfaction; $\mathrm{BD5}=$ moderate/marked body dissatisfaction; BD6 = marked body dissatisfaction.

i"Odds ratios were adjusted for the following covariates: age, BMI; marital status; employment status; level of education; parity; first language, country of birth and possession of private health insurance.

iii**** $p<0.001,{ }^{* *} p<0.01,{ }^{*} p<0.05$.

ivWHOQOL-BREF Psychological Functioning Subscale (QOL-P) items.

Positive Feelings: How much do you enjoy life? (Not at all; A little; A moderate amount; Very much; An extreme amount).

Spirituality: To what extent do you feel your life to be meaningful? (Not at all; A little; A moderate amount; Very much; An extreme amount).

Thinking: How well are you able to concentrate? (Not at all; A little; A moderate amount; Very much; Extremely).

Self-esteem: How satisfied are you with yourself? (Very dissatisfied; dissatisfied; Neither satisfied nor dissatisfied; Satisfied; Very satisfied).

Negative feelings: How often do you have negative feelings such as blue mood, despair, anxiety, depression? (Never; Seldom; Quite often; Very often; Always).

'WHOQOL-BREF Social Relationships Subscale (QOL-S) items.

Personal relationships: How satisfied are you with your personal relationships? (Very dissatisfied; dissatisfied; Neither satisfied nor dissatisfied; Satisfied; Very satisfied).

Sexual activity: How satisfied are you with your sex life? (Very dissatisfied; dissatisfied; Neither satisfied nor dissatisfied; Satisfied; Very satisfied).

Social support: How satisfied are you with the support you get from your friends? (Very dissatisfied; dissatisfied; Neither satisfied nor dissatisfied; Satisfied; Very satisfied).

viWHOQOL-BREF Overall quality of life item: How would you rate your quality of life? (Very poor; Poor; Neither poor nor good; Good; Very good).

viisF-12 Physical Component Summary Scale (PCS) items.

General health: In general, would you say your health is ...? (Excellent; Very good; Good; Fair; Poor).

Accomplish less: During the past four weeks, have you accomplished less than you would like as a result of your physical health? (Yes, No).

Limited in kind: During the past four weeks, were you limited in the kind or work or other regular activities you do as a result of your physical health? (Yes, No).

Moderate activities: Does your health now limit you in moderate activities, such as moving a table, pushing a vacuum cleaner, bowling or playing golf?

(Yes, limited a lot; Yes, limited a little; No, not limited at all).

Climb several flights: Does your health now limit you in climbing several flights of stairs? (Yes, limited a lot; Yes, limited a little; No, not limited at all).

Pain-interfere: During the past four weeks, how much did pain interfere with your normal work (including both work outside the home and housework)?

(Not at all; A little bit; Moderately; Quite a bit; Extremely).

viiisF-12 Mental Component Summary Scale (MCS) items.

Accomplish less: During the past four weeks, have you accomplished less than you would like to as a result of any emotional problems, such as feeling depressed or anxious)? (Yes, No).

Not careful: During the past four weeks, did you not do work or other regular activities as carefully as usual as a result of any emotional problems (such as feeling depressed or anxious? (Yes, No).

Peaceful: How much of the time during the past four weeks have you felt calm and peaceful? (All of the time; Most of the time; A good bit of the time; Some of the time; A little of the time; None of the time).

Energy: How much of the time during the past four weeks did you have a lot of energy? (All of the time; Most of the time; A good bit of the time; Some of the time; A little of the time; None of the time).

Blue/sad: How much of the time during the past four weeks have you felt downhearted and blue? (All of the time; Most of the time; A good bit of the time; Some of the time; A little of the time; None of the time).

Social-time: During the past four weeks, how much of the time has your physical health or emotional problems interfered with your social activities (like visiting with friends, relatives, etc)? (All of the time: Most of the

time; Some of the time: A little of the time; None of the time). 
of current public health messages concerning the adverse health consequences of obesity, to find that at least some women who are dissatisfied with their bodies believe themselves to be overweight and/or "unhealthy" when in fact they may be neither [44-46]. Finally, BD may be associated with lower levels of physical activity, hence poorer physical health, due to avoidance of bodily exposure $[47,48]$.

Because the links between $\mathrm{BD}$ and eating disorder symptoms are particularly strong [18], and because there is good evidence that eating disorder symptoms are associated with marked impairment in quality of life in women [22,23], post-hoc analysis was conducted to address the possibility that the impairment in quality of life associated with BD observed in the present study might have been due, at least in part, to an association between $\mathrm{BD}$ and eating disorder symptoms. However, there was little evidence to support this hypothesis. Effect sizes for certain associations were marginally reduced when the original analysis was repeated controlling for the occurrence of eating disorder symptoms (among participants with high levels of BD). Otherwise, the findings were unchanged.

The latter finding is notable because eating disorder prevention programs have generally been more successful in reducing the occurrence of $\mathrm{BD}$ and related constructs than eating disorder symptoms per se [49]. The present findings suggest that health promotion programs that are successful in reducing the occurrence of $\mathrm{BD}$ are likely to have substantial benefits in terms of individual and community well-being irrespective of whether they are successful in reducing the occurrence of eating disorder symptoms. In our view, both BD and eating disorder symptoms warrant greater attention as public health problems, particularly in the context of obesity prevention $[12,16,23]$. However, BD may be the more rational target for health promotion efforts given that it is: (i) a potent risk factor for various adverse health outcomes; (ii) common; and (iii) associated with considerable distress and disability in its own right.

\section{Study limitations and other methodological considerations}

At least three limitations of the present study need to be considered when interpreting the findings. First, the assessment of BD was confined to two items assessing participants' subjective dissatisfaction with their weight or shape. The advantage of this assessment was that it encompassed a brief, relatively unambiguous measure suitable for use in an epidemiological study. However, it would be helpful to replicate the present findings using a more sophisticated, multidimensional measure of BD [12,50].

Second, the generalizability of the present findings is constrained by the choice of study population, namely, young adult women from an urbanized and comparatively affluent region of Australia. Hence, replication of the present findings in women of different ages and in women and men from more diverse backgrounds would be a useful contribution to future research [12,15,51]. The demonstration of similar associations in other study populations would further strengthen the case for recognition of BD as a public health problem. Replication of the present study method in a population-based sample of men would be of particular interest. Although anecdotal evidence has been taken to infer that the prevalence of $\mathrm{BD}$ and/or its impact on mental health may be increasing in men, until recently there has been little in the way of empirical evidence to support either contention [12,52].

Third, the method employed to determine that the observed associations between BD and quality of life impairment were not accounted for by an association between BD and eating disorder symptoms, namely, controlling for participants with a high levels of eating disorder symptoms ("probable eating disorder cases"), cannot be considered definitive. Since eating disorder symptoms, like BD, occur on a continuum, it is possible that the occurrence of lower levels of symptomatology among remaining participants influenced the observed associations between BD and quality of life. Although it would have been possible to employ the EDE-Q global score as continuous covariate, this course was not taken because the EDE-Q global score is primarily a measure of concerns about weight, shape and eating and as such is highly correlated with the items that assess $\mathrm{BD}(\mathrm{r}=0.85$ in the present study population) $[28,29]$. By definition, eating-disordered behavior entails, in addition to attitudinal features such as the "undue influence of weight or shape on self-evaluation", the regular occurrence of one or more eating disorder behaviors [53].

Finally, this was a cross-sectional study. Conceivably, poor quality of life could be conducive to BD or associations might exist in both directions [54]. Although the direction of the observed associations cannot be determined on the basis of the present study, it may be noted that findings from prospective epidemiological studies strongly support the role of $\mathrm{BD}$ in predicting adverse health outcomes, whereas evidence for the role of low self-esteem, depressive mood and other such outcomes in predicting BD is less compelling [13,54]. Notable strengths of the current study were the recruitment of a large, general population sample of women, the inclusion of two different, widely-used measures of quality of life and the assessment of eating disorder symptoms in addition to BD.

\section{Conclusions}

In women, $\mathrm{BD}$ is associated with marked impairment in aspects of quality of life relating to mental health and 
psycho-social functioning and at least some aspects of physical health, independent of its association with body weight and eating disorder symptoms. Given this, and given its high prevalence, greater attention may need to be given to $\mathrm{BD}$ as a public health problem. The fact that BD is "normative" should not be taken to infer that it is benign.

\section{Ethics approval}

The research was conducted with the approval of the ACT Human Research Ethics Committee.

\section{Competing interests}

The authors declare that they have no competing interests.

\section{Authors' contributions}

$J M$ was responsible for the design and conduct of the research as well as data processing, initial data analysis and manuscript preparation. DM conducted supplementary data analysis and assisted with interpretation of this analysis. BR, PH and CO contributed to the design and conduct of the research and to critical revision of an earlier version of the manuscript. BR contributed to data analysis and interpretation. All authors read and approved the final manuscript.

\section{Acknowledgements}

The Health and Well-Being of Female ACT Residents Study was funded by The Canberra Hospital Private Practice Fund, ACT Health and Community Care and ACT Mental Health.

\section{Author details}

${ }^{1}$ Research School of Psychology, Australian National University, Canberra ACT 0200, Australia. ${ }^{2}$ School of Medicine, University of Western Sydney, Campbelltown, Australia. ${ }^{3}$ Department of Psychology, University of Hawaii at Manoa, Honolulu, USA. ${ }^{4}$ School of Medicine, University of Western Sydney, Campbelltown, Australia. ${ }^{5}$ School of Medicine, James Cook University, Townsville, Australia. ${ }^{6}$ Rural Clinical School, Medical School, Australian National University, Canberra, Australia. ${ }^{7}$ Australian Demographic \& Social Research Institute, Australian National University, Canberra, Australia.

Received: 8 June 2012 Accepted: 25 September 2013

Published: 3 October 2013

\section{References}

1. Murray CJL, Lopes AD: Global mortality, disability, and the contribution of risk factors: global burden of disease study. Lancet 1997, 349:1436-1442.

2. Kessler RG, Frank RG: The impact of psychiatric disorders on work loss days. Psychol Med 1997, 27:861-873.

3. Sanderson $\mathrm{K}$, Andrews G: Prevalence and severity of mental health-related disability and relationship to diagnosis. Psych Serv 2002, 53:80-86.

4. Orley J, Saxena S, Hermann H: Quality of life and mental illness: reflections from the perspective of the WHOQOL. Br J Psychiatry 1998, 172:291-293.

5. Coelho R, Ramos S, Prata J, Bettencourt P, Ferreira A, Cerqueira-Gomes M: Heart failure and health related quality of life. Clin Pract Epidemiol Ment Health 2005, 1:19. doi: 10.1186/1745-0179-1-19.

6. Katschnig $\mathrm{H}$ : Quality of life in mental disorders: challenges for research and clinical practice. World Psychiatr 2006, 5:139-145.

7. DeSalvo KB, Fan VS, McDonell MB, Fihn SD: Predicting mortality and healthcare utilization with a single question. Health Serv Res 2005, 40:1234-1246.

8. Wade TJ, Guo JJ: Linking improvements in health-related quality of life to reductions in Medicaid costs among students who use school-based health centers. Am J Public Health 2010, 100:1611-1616.

9. Diener E, Chan MY: Happy people live longer: subjective well-being contributes to health and longevity. Appl Psychol Health Well Being 2011, 3:1-43.

10. Grogan S: Body image: understanding body dissatisfaction in men, women, and children. London, UK: Routledge; 2008.
11. Rodin J, Silberstein L, Striegel-Moore R: Women \& weight: a normative discontent. In Psychology and gender. Edited by Sonderegger TB. Lincoln, NE: University of Nebraska Press; 1985:267-307.

12. Mond JM, van den Berg P, Boutelle $K$, Neumark-Sstainer D, Hannan PJ: Obesity, body dissatisfaction, and psycho-social functioning in early and late adolescence: findings from the Project EAT Study. J Adolesc Health 2011, 48:373-378.

13. Neumark-Sstainer D, Paxton SJ, Hannan PJ, Haines J, Story M: Does body satisfaction matter? Five-year longitudinal associations between body satisfaction and health behaviors in adolescent females and males. J Adolesc Health 2006, 39:244-251.

14. Pimenta AM, Sánches-Villegas A, Bes-Rastrollo M, Lópes CN, MartínesGonsáles MA: Relationship between body image disturbance and incidence of depression: the SUN prospective cohort. BMC Public Health 2009, 9:1. doi: 10.1186/1471-2458-9-1.

15. Santos Silva DA, Nahas MV, De Sousa TF, Del Duca GF, Peres KG: Prevalence and associated factors with body image dissatisfaction among adults in southern Brazil: a population-based study. Body Image 2011, 8:427-431.

16. Mond JM, Rodgers B, Hay PJ, Owen C: Obesity and impairment in psychosocial functioning: the mediating role of eating-disordered behavior. Obesity 2007, 15:2769-2779.

17. Paxton SJ: Public health interventions for body dissatisfaction and eating disorders. In Prevention of eating-related disorders: research, advocacy and policy change. Edited by McVey G, Levine M, Piran N, Ferguson B. Waterloo, ON: Wilfred Laurier University Press. in press.

18. Stice E, Shaw HE: Role of body dissatisfaction in the onset and maintenance of eating pathology: a synthesis of research findings. J Psychosom Res 2002, 53:985-993.

19. Meland E, Haugland S, Briedablik H-J: Body image and perceived health in adolescence. Health Ed Res 2007, 22:342-350.

20. Mond JM, Hay PJ: Functional impairment associated with eating disorder behaviors in a community sample of women and men. Int J Eat Disord 2007, 40:391-398.

21. Muennig P, Jia H, Lee R, Lubetkin E: I think therefore I am: perceived ideal weight as a determinant of health. Am J Public Health 2008, 98:501-506.

22. Mond JM, Rodgers B, Hay PJ, Owen C: Mental health impairment associated with eating-disordered behaviour in a community sample of women. J Mental Health 2011, 20:456-466.

23. Mond JM, Hay PJ, Rodgers B, Owen C: Comparing the health burden of overweight and eating-disordered behavior in young adult women. J Women's Health 2009, 18:1081-1089.

24. Mitchison D, Hay PJ, Slewa-Younan S, Mond JM: Time trends in population prevalence of eating disorder behaviors and their relationship to quality of life. PLOS One 2012, 7:e48450. doi: 10.1371/ journal.pone.0048450.

25. Vallance JK, Latner JD, Gleaves DH: The relationship between eating disorder psychopathology and health-related quality of life within a community sample. Qual Life Res 2011, 20:675-682.

26. Mond JM, Rodgers B, Hay PJ, Korten A, Owen C, Beumont PJV: Disability associated with community cases of commonly occurring eating disorders. Aust N Z J Public Health 2004, 28:246-251.

27. Mond JM, Hay PJ, Rodgers B, Owen C, Crosby R, Mitchell JE: Use of extreme weight control behaviors with and without binge eating in a community sample of women: implications for the classification of bulimic-type eating disorders. Int J Eat Disord 2006, 39:294-302.

28. Mond JM, Hay PJ, Rodgers B, Owen C: Eating Disorder Examination Questionnaire (EDE-Q): norms for young adult women. Behav Res Ther 2006, 44:53-62.

29. Mond JM, Hay PJ, Rodgers B, Owen C, Beumont PJV: Validity of the Eating Disorder Examination Questionnaire (EDE-Q) in screening for eating disorders in community samples. Behav Res Ther 2006, 42:551-567.

30. Mond JM, Rodgers B, Hay PJ, Owen C, Beumont PJV: Effects of questionnaire length and mode of delivery on response rates in an epidemiological study of eating-disordered behaviour. J Clin Epidemiol 2004, 57:1167-1171.

31. Fairburn CG, Beglin SJ: Assessment of eating disorders: interview or self-report questionnaire? Int J Eat Disord 1994, 16:363-370.

32. Ware JE, Kosinski M, Keller SD: A 12-item short-form health survey: construction of scales and preliminary tests of reliability and validity. Med Care 1996, 34:220-233. 
33. WHOQOL Group, WHOQOL Group (1998): Development of the World Health Organisation WHOQOL-BREF quality of life assessment. Psychol Med 1998, 28:551-558.

34. Skevington SM, Lofty M, O'Connell KA: The World Health Organization's WHOQOL-BREF quality of life assessment: psychometric properties and results of an international field trial. A report from the WHOQOL Group. Qual Life Res 2004, 13:299-310.

35. Mond JM, Hay PJ, Rodgers B, Owen C, Beumont PJV: Relationships between exercise behaviour, eating-disordered behaviour and quality of life in a community sample of women: when is exercise 'excessive'? Eur Eat Disord Rev 2004, 12:265-272.

36. Mond JM, Hay PJ, Rodgers B, Owen C: Quality of life impairment in a community sample of women with eating disorders. Aust N Z J Psychiatry 2012, 46:561-568.

37. Windsor TD, Rodgers B, Butterworth P, Anstey KJ, Jorm AF: Measuring physical and mental health using the SF-12: implications for community surveys of mental health. Aust N S J Psychiatry 2006, 40:797-803.

38. Mond JM, Hay PJ, Paxton SJ, Rodgers B, Owen C, Quirk F, et al: Eating disorders mental health literacy in low risk, high risk, and symptomatic women: implications for health promotion programs. Eat Disord 2010, 18:267-285

39. Mond JM, Hay PJ: Dissatisfaction vs overvaluation in a community sample of women. Int J Eat Disord 2011, 44:721-726.

40. American Psychiatric Association: Diagnostic and statistical manual of mental disorders (DSM-5). 5th edition. Washington, DC: American Psychiatric Association; 2013.

41. Mond JM, Hay PJ, Rodgers B, Owen C: Binge eating with and without the "undue influence of weight or shape on self-evaluation": implications for the diagnosis of binge eating disorder. Behav Res Ther 2007, 45:929-938.

42. Richardson JTE: Eta squared and partial eta squared as measures of effect size in educational research. Ed Res Rev 2011, 6:135-147.

43. Bardone AN, Vohs KD, Abramson LY, Heatherton TF, Joiner TE: The confluence of perfectionism, body dissatisfaction, and low self-esteem predicts bulimic symptoms: clinical implications. Behav Ther 2000, 31:265-280.

44. Austin SB: Fat, loathing and public health: the complicity of science in a culture of disordered eating. Cult Med Psychiat 1999, 23:245-268.

45. Burns M, Gavey N: "Healthy weight" at what cost? "Bulimia" and a discourse of weight control. J Health Psychol 2004, 9:549-565.

46. O'Hara L, Gregg J: The war on obesity: a social determinant of health. Health Prom J Aust 2006, 17:260-263.

47. Ball K, Crawford D, Owen N: Too fat to exercise? Obesity as a barrier to physical activity. Aust N S J Public Health 2000, 24:331-333.

48. Liechty T, Freeman P, Zabriskie R: Body image and beliefs about appearance: constraints on the leisure of college-age and middle-age women. Leis Sci 2006, 28:311-330.

49. Stice E, Shaw HE: Eating disorder prevention program: a meta-analytic review. Psychol Bull 2004, 130:206-227.

50. Cash TF, Morrow JA, Hrabosky Jl, Perry AA: How has body image changed? A cross-sectional investigation of college women and men from 1983 to 2001. J Consult Clin Psychol 2004, 72:1081-1089.

51. van den Berg PA, Mond JM, Eisenberg ME, Ackard D, Neumark-Sstainer D: The link between body dissatisfaction and self-esteem in adolescents: similarities across gender, weight status, race and socioeconomic status. J Adolesc Health 2010, 47:290-296.

52. Mond JM, Mitchison D, Hay PJ: Eating disordered behavior in men: prevalence, impairment in quality of life, and implications for prevention and health promotion. In Current findings on males with eating disorders. Edited by Cohn L, Lemberg R. London, UK: Routledge; 2013:195-208.

53. Hay PJ: What is an eating disorder? Implications for current and future diagnostic criteria. Aust N Z J Psychiatry 2013, 47:208-211.

54. Paxton SJ, Eisenberg ME, Neumark-Sstainer D: Prospective predictors of body dissatisfaction in adolescent girls and boys: a five-year longitudinal study. Dev Psychol 2006, 42:888-899.

doi:10.1186/1471-2458-13-920

Cite this article as: Mond et al:: Quality of life impairment associated with body dissatisfaction in a general population sample of women. BMC Public Health 2013 13:920.

\section{Submit your next manuscript to BioMed Central and take full advantage of:}

- Convenient online submission

- Thorough peer review

- No space constraints or color figure charges

- Immediate publication on acceptance

- Inclusion in PubMed, CAS, Scopus and Google Scholar

- Research which is freely available for redistribution 